\title{
A NOTE ON WEIGHTED ESTIMATES FOR BILINEAR FRACTIONAL INTEGRAL OPERATORS
}

\author{
YASUO KOMORI-FURUYA
}

Abstract. De Napoli, Drelichman and Durán (2011) proved weighted estimates for the fractional integral operators. Komori-Furuya and Sato (2020) proved weighted estimates for bilinear fractional integral operators. We show that their results are optimal by giving counterexamples.

Mathematics subject classification (2010): 42B20, 42B25.

Keywords and phrases: Bilinear fractional integral, weighted estimates, Stein-Weiss inequality.

\section{REFERENCES}

[1] J. DuOANDIKOETXEA, Fractional integrals on radial functions with applications to weighted inequalities, Annali di Matematica 192, 553-568 (2013).

[2] P. De Nápoli, I. Drelichman and R. G. Durán, On weighted inequalities for fractional integrals of radial functions, Ill. J. Math., 55 (2), 575-587 (2011).

[3] L. Grafakos, Classical Fourier Analysis, 2nd ed. Graduate Texts in Math. No. 249, Springer (2008).

[4] Y. KOMORI-FURUYA AND E. SATO, Weighted estimates of multilinear fractional integral operators for radial functions, Math. Ineq. Appl. 23 (1), 245-256 (2020).

[5] B. S. RubIN, One-dimensional representation, inversion and certain properties of Riesz potentials of radial functions (Russian), Mat. Zametki 34 (4), 521-533 (1983). English translation: Math. Notes 34, 751-757 (1983).

[6] E. M. Stein AND G. Weiss, Fractional integrals on n-dimensional Euclidean space, J. Math. Mech. 7, 503-514 (1958). 